\title{
Heat transfer of impinging multijet system An application of the quantitative thermography
}

\author{
by J.M. BUCHLIN (*) and M. DUBOIS $(* *)$
}

$\left(^{*}\right)$ von Karman Institute for Fluid Dynamics, Rhode-Saint-Genèse, Belgium.

$\left.{ }^{* *}\right)$ Cockerill Sambre, Branche Phenix, Flemalle, Belgium.

\begin{abstract}
The paper deals with an infrared thermographic technique to find the heat transfer coefficient in the impacting region of an array of slotted jets. The IR method allows to study the effect of the geometrical arrangement and fluid flow parameters upon the system effectiveness. The results are in good agreement with correlation obtained from mass transfer technique. Their applicability to industrial situation is illustrated.
\end{abstract}

\section{Nomenclature}

\begin{tabular}{lll}
$\frac{e}{h}$ & strip thickness & $\mathrm{m}$ \\
$h_{w}$ & average heat transfer coefficient & $\mathrm{W} / \mathrm{m}^{2}{ }^{\circ} \mathrm{C}$ \\
$k_{a}$ & wall heat transfer coefficient & $\mathrm{W} / \mathrm{m}^{2} \cdot{ }^{\circ} \mathrm{C}$ \\
$\frac{L}{N u}$ & gas thermal conductivity & $\mathrm{W} / \mathrm{m} \cdot{ }^{\circ} \mathrm{C}$ \\
$R e_{j}$ & length of the cooler & $\mathrm{m}$ \\
$q_{\ell}$ & average Nusselt number & $\mathrm{y}$ \\
$q_{w}$ & gas jet Reynolds number & $\mathrm{y}$ \\
$S$ & heat loss & $\mathrm{W} / \mathrm{m}^{2}$ \\
$T_{i}$ & wall heat flux & $\mathrm{W} / \mathrm{m}^{2}$ \\
$T_{j r}$ & nozzle hydraulic diameter & $\mathrm{m}$ \\
$T_{o}$ & inlet strip temperature & ${ }^{\circ} \mathrm{C}$ \\
$T_{w}$ & gas jet temperature & ${ }^{\circ} \mathrm{C}$ \\
$U$ & outlet strip temperature & ${ }^{\circ} \mathrm{C}$ \\
$U_{j}$ & wall temperature & ${ }^{\circ} \mathrm{C}$ \\
$W$ & strip velocity & $\mathrm{m} / \mathrm{s}$ \\
$x$ & initial gas jet velocity & $\mathrm{m} / \mathrm{s}$ \\
$Z$ & nozzle spacing & $\mathrm{m}$ \\
$\nu_{a}$ & distance along the median axis & $\mathrm{m}$ \\
\hline$C_{p}$ & nozzle to plate distance & $\mathrm{m}$ \\
& gas kinematic viscosity & $\mathrm{m} / \mathrm{s}$ \\
& strip heat capacity & $\mathrm{J} / \mathrm{m}^{3} \cdot{ }^{\circ} \mathrm{C}$
\end{tabular}

\section{Introduction}

Because of their ability to produce high local transport coefficients, impinging jets play an important role in industrial processes where heat and/or mass transfer prevail. The industrial application presently emphasized is the galvanizing technique. In such a process, a continuously moving steel strip dives into a bath of melt zinc that it leaves coated with a thin liquid film. After gas wiping to adjust the final coating thickness, the band is cooled as fast as possible by a battery of slotted nozzles blowing air normally to the moving ribbon. The cooling optimization requires identifying the basic parameters that control the heat transfer coefficient of this system. Practical considerations lead to study arrays of jets emphasizing the effect of their mutual interaction. Different experimental techniques have been proposed to determine the local and the average heat transfer coefficients on the target surface. Most of the experimental procedures are based on the use of heated or cooled flat plate instrumented with a finite number of temperature sensors 


\section{http://dx.doi.org/10.21611/qirt.1992.017}

and/or calorimeters. Mass transfer analogy involving evaporation or sublimation or diffusion controlled electrolysis process has been also adopted.

The technique presented in this paper belongs to the thermo-optical class and relies upon the utilization of constant emissivity heated-flat-foil. The temperature field is measured with an infrared thermographic analyser. The recent progress made in infrared imaging systems has initiated significantly the development and the application of thermographic techniques to fluid flow problems [1]. The applicability of such a method to complex flow situations is illustrated in the present paper through recent experimental results obtained at the VKI on a multijet system.

\section{Test apparatus and experimental procedure}

The effect of parameters as the nozzle-to-plate distance, nozzle spacing and nozzle Reynolds number on the performance of this multijet heat exchanger is investigated experimentally using the setup sketched in figure 1.

Several identical slotted-nozzles, with an hydraulic diameter $S$, are equally spaced by a distance $W$ and at a height $Z$ from the plate. They are supplied with compressed air from a regulated plenum chamber.

The constant heat-flux flat plate is $0.70 \mathrm{~m}$ long and $0.30 \mathrm{~m}$ wide. It is constructed from a circuit board - EGS 102 type GE - made of 35 micrometers copper foil coated by an epoxy FR-4 sheet of $0.0015 \mathrm{~m}$ thick. The copper face of the plate is machined to produce lengthwise groves. They form a wavily continuous electrical resistance that is connected to an AC generator. The Joule heating is controlled by variac and measured by ammeter and voltmeter. The design of the heated flat plate has been optimized to provide good uniformity of the heat flux. The insulating face of the plate is exposed to the impinging flow. The other side, painted black, is sampled by a video infrared camera. The IR radiometer used is the Probeye - Model 7300 . The detector assembly consists of a 30-element array constructed of mercury cadmium telluride, thermoelectrically cooled by Peltier effect. It operates in the 3.2 to $5 \mu \mathrm{m}$ spectrum with a sensivity of $0.1{ }^{\circ} \mathrm{C}$ at 0.01 cycles/mrad (manufacturer specifications). Although the camera allows direct measurement of the wall temperature, the IR system is calibrated previously to each test. For that, copper-constantan junctions are flush-mounted in the epoxy jet facing layer to provide information for the determination of the absolute temperature - intensity calibration curve of the thermograms.

The principle of the technique demands to adjust a constant energy dissipation per unit area, $q_{w}$, from Joule heating and to measure the local steady state distribution of the surface temperature, $T_{w}(x, y)$. The local convective heat transfer coefficient, $h_{w}(x, y)$, is determined as following :

$$
h_{w}(x, y)=\frac{q w(x, y)-q_{\ell}(x, y)}{T_{w}(x, y)-T_{j r}}
$$

$q_{\ell}$ states for the heat loss due to conduction and radiation effects. $T_{j r}$ is the recovery temperature of the air jet. For most of the present experimental operating conditions, $q_{\ell}$ does not exceed $10 \%$ of the total heat flux and $T_{j r}$ does not differ significantly from the air temperature measured in the plenum chamber.

The infrared pictures are recorded on video tape that is replayed frame by frame and analyzed by means of a specific software set up on a Digital Image Processing system. The results are the temperature profiles and the subsequent heat transfer coefficient distributions. Error analysis indicates that about $10 \%$ of uncertainty are assigned to the value of the convective heat coefficient. 


\section{http://dx.doi.org/10.21611/qirt.1992.017}

\section{Typical results}

Preliminary tests have proved that the resulting thermogram is a faithful representation of the impinging flow pattern. A typical digitized infrared picture of the temperature field characterizing the impact zone of two nearby jets is displayed in figure $A^{*}$. The distortion of the isotherm contours depicted in this thermogram denotes the spanwise variation of the flow rate in the jet due to a non uniform orifice diameter of the nozzle.

The associated temperature and convective heat transfer profiles along the median axis $x^{\prime} x$ are plotted in figure 2. For a practical purpose like the design of multijet heat exchanger it is more convenient to calculate an average heat transfer coefficient, $\bar{h}$, from the local distribution :

$$
\bar{h}=\frac{1}{W} \int_{-W / 2}^{+W / 2} h d x
$$

Typical results are shown in figure 3. In terms of the average Nusselt number $\overline{N u}=\bar{h} S / k_{a}$ plotted versus the jet Reynolds number $R e_{j}=U_{j} S / \nu_{a}$ based on the mean velocity at the exit of the nozzle, $U_{j} . k_{a}$ and $\nu_{a}$ are the thermal conductivity and the kinematic viscosity of the air respectively.

Typical IR experimental results are compared with the mass transfer data obtained by MARTIN [2]. Good agreement has been observed between the present measurements and the predictions from the Martin correlation when the parameters satisfy the following validity ranges :

$$
3000 \leq R e \leq 90000, \quad 2 \leq \frac{W}{S} \leq 25, \quad 2 \leq \frac{Z}{S} \leq 20 .
$$

To assess the applicability of the laboratory IR-correlation to an industrial configuration, on-line measurements of the galvanized-strip temperature have been performed. The mean temperatures along the width of the band at the inlet, $T_{i}$ and at the outlet, $T_{o}$ of the cooling unit are measured with contact thermocouple devices for different air jet velocities. The interpretation of the data relies upon the classical analytical relation that describes the cooling of the strip [3] :

$$
\bar{h}=\frac{e U \overline{\rho C_{p}}}{2 L} \ln \left(\frac{T_{i}-T_{j r}}{T_{o}-T_{j r}}\right)
$$

where $e, \overline{\rho C_{p}}$ and $U$ are the thickness, the heat capacity per unit volume and the velocity of the band respectively. $L$ is the length of the cooler.

The results plotted in figure 4 confirm the applicability of the IR correlation even for the high jet Reynolds number reached in the present galvanizing line.

\section{Conclusions}

A quantitative thermographic technique to determine the local heat transfer coefficient at the impact of a multijet system on a heated flat is presented and illustrated by typical results. This non intrusive technique allows capturing and quantifying all the effects of the flow parameters on the heat transfer coefficient. Good agreement between quantitative thermography and mass transfer technique is observed. The applicability of the laboratory data to an industrial galvanizing line is demonstrated. Associated with information recording and digital processing units, the infrared imaging system is a powerful tool for research in fluid dynamic problems. 


\section{REFERENCES}

[1] BUCHLIN (J.-M.).- Digital image processing applied to fluid dynamic problems. AGARD PEP 67 th Symp. on Advanced Instrumentation for Aero Engine Components, Philadelphia, USA, May 1986.

[2] MARTIN (H.).- Heat and mass transfer between impinging gas jets and solid surface. Adv.Heat Transfer, Vol. 13, 1977, p. 1-60.

[3] BUCHLIN (J.-M.) and TUFFIER (P.). - Modèle théoriquie d'un refroidisseur à multi-jets pour tôle galvanisée. von Karman Institute CR, 1990-09/EA, décembre 1990.
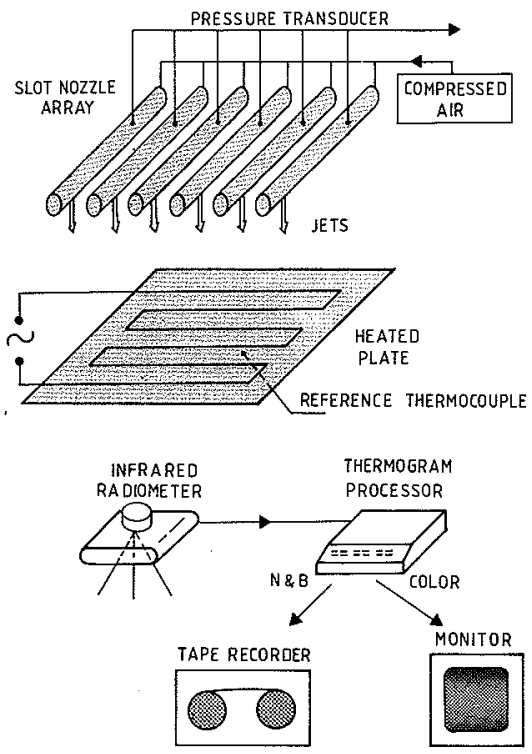

Fig. 1. - Layout of the jet heat transfer test setup

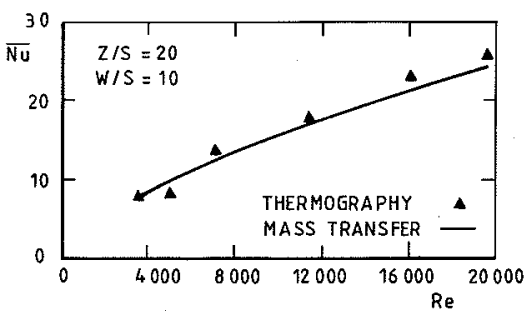

Fig. 3. - Average Nusselt number of multijet system

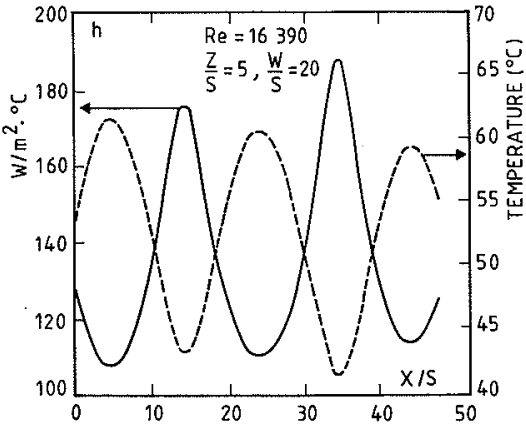

Fig. 2. - Wall temperature and associated heat transfer coefficient

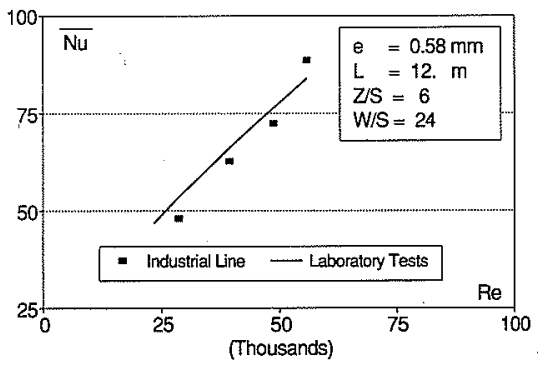

Fig. 4. - Applicability of the IR correlation to a galvanizing line 